\title{
Drug Effects on Myasthenia Gravis
}

\section{Rehman HU*}

\section{Department of Medicine, Regina Qu'Appelle Health Region, Regina General Hospital, Canada}

In this issue of Clinical Case Reports, Nadig [1] describe a case of myasthenia gravis (MG) unmasked after treatment with beta-blockers for hypertrophic cardiomyopathy. MG presents at an age when comorbid conditions are common and require treatment with multiple medications. In addition, heart disease may be a manifestation of MG. In one study, $16 \%$ of 108 patients with MG showed signs of heart disease, mainly arrhythmia [1]. MG patients have $70-90 \%$ reduction in the number of AChR in the neuromuscular junction. Treatment of some of these cardiac and other coincidental conditions in MG patients may have deleterious effects on myasthenia gravis. Drug-induced neuromuscular blockade therefore has the potential of worsening MG or precipitating myasthenic crisis in these patients. It is therefore essential that physicians looking after MG patients should know how commonly used drugs may effect neuromuscular transmission.

Neurological signals are conveyed by the release of acetylcholine (Ach) at the synaptic junction from pre-synaptic vesicles in the nerve terminals. Ach then binds to Ach receptors (AChRs). Acetylcholine esterase hydrolyses Ach. Choline undergoes pre-synaptic re-uptake and used to regenerate Ach. In MG, antibodies bind to AChRs at the motor end plate and thus hinder impulse transmission [2]. Several drugs can interrupt this sequence of events at various points. For example, non-depolarizing neuromuscular blocking drugs and aminoglycosides block post-synaptic AChRs thereby preventing binding of Ach to these receptors. Post-operative respiratory depression is the most common presentation in MG patients treated with aminoglycosides. Lithium and magnesium may prevent release of Ach from pre-synaptic vesicles [3].

Penicillamine has caused iatrogenic MG. MG has been reported in 1 to $7 \%$ of all patients treated with penicillamine [4].

$90 \%$ of these patients have AChR antibodies which are antigenically similar to those found in patients with idiopathic MG $[5,6]$. It is therefore thought that penicillamine causes or worsens existing MG by binding to AChR at the motor end plate and thus blocking Ach's access to these receptors. Onset of symptoms typically occurs from 2 to 12 months after initiation of penicillamine and symptoms usually resolve in 2 to 6 months after discontinuation of the drug. Treatment with interferon alfa has also been reported to induce MG [7].

Magnesium interferes with neuromuscular transmission by inhibiting Ach release and competitively blocks calcium entry at the motor nerve terminal. Patients with both MG and Lambert-Eaton syndrome have been reported to have worsening muscle weakness despite normal or mildly elevated serum levels [7].

Phenytoin reduces pre-synaptic action potential amplitude and has been reported to cause MG-like symptoms, confirmed by positive results to edrophonium test $[8,9]$. Among cardiac drugs, cibenzoline has been reported to cause MG-like syndrome in a number of patients with renal impairment. All these patients had high serum concentrations of the drug since the drug [10]. Oxpranolol and propranolol have been implicated in worsening of MG [11] Indeed, MG worsened after use of timolol eye drops in a number of case reports [12] Calcium channel blockers have been proposed to effect neurotransmission by inhibition of potassium outflow from cells at motor endplate. Verapamil has caused worsening of MG confirmed by EMG which showed reduction in action potential amplitude by one fifth and a decrease in motor unit potential by one fourth to one half [13]. Nifedipine and felodipine have also been reported to cause increase weakness in MG [14]. Other antiarrhythmic drugs that should be used with caution in MG are quinidine, disopyramide, procainamide and propafenone.

Apart from aminoglycosides, various other antibiotics may also worsen MG. These include ciprofloxacin, imipenem/cilastatin, ampicillin and erythromycin. In most of these patients symptoms resolved promptly after stopping the drug and recurred with a re-challenge. In patients treated with imipenem/cilastatin and erythromycin, edrophonium test results were positive. Patient treated with erythromycin also had AChR antibodies $[15,16]$.

Chloroquine may cause worsening of MG via induction of autoimmunity, since AChR antibodies have been detected in patients treated with chloroquine who developed muscle weakness whilst taking chloroquine [17].

Contrast media used in radiologic procedures may also aggravate neuromuscular weakness in MG patients. Frequency of contrastinduced myasthenic weakness is estimated to be less than $2 \%$ [18].

In conclusion, at least 30 different drugs have been reported to cause, worsen or unmask a pre-existing MG. These medications should be used with caution in patients known to have MG. Patients on these medications should be monitored very closely for worsening of muscle function which may manifest as respiratory depression, ptosis or dysphagia.

\section{References}

1. Nadig S, Kapoor A, AgrawalR, Mishra A (2014) Unmasking of Occult Myasthenia Gravis in Hypertrophic Cardiomyopathy by Beta Blockers.J Clin Case Rep 4: 350.

2. Maselli RA (1994) Pathophysiology of myasthenia gravis and Lambert-Eaton syndrome. Neurol Clin 12: 285-303.

3. Wittbrodt ET (1997) Drugs and myasthenia gravis. An update. Arch Intern Med 157: 399-408.

4. Andonopoulos AP, Terzis E, Tsibri E, Papasteriades CA, Papapetropoulos T (1994) D-penicillamine induced myasthenia gravis in rheumatoid arthritis: an unpredictable common occurrence? Clin Rheumatol 13: 586-588.

5. Tzartos SJ, Morel E, Efthimiadis A, Bustarret AF, D'Anglejan J, et al. (1988) Fine antigenic specificities of antibodies in sera from patients with D-penicillamineinduced myasthenia gravis. Clin Exp Immunol 74: 80-86.

6. Pascuzzi RM (1998) Drugs and toxins associated with myopathies. Curr Opin Rheumatol 10: 511-520.

7. Lensch E, Faust J, Nix WA, Wandel E (1996) Myasthenia gravis after interferonalpha treatment. Muscle Nerve 19: 927-928.

8. NORRIS FH Jr, Colella J, Mcfarlin D (1964) Effect of diphenylhydantoin on neuromuscular synapse. Neurology 14: 869-876.

*Corresponding author: HU Rehman, Department of Medicine, Regina Qu'Appelle Health Region, Regina General Hospital, 1440 - 14th Avenue, Regina, SK, S4P 0W5, Canada, E-mail: habib31@sasktel.net

Received April 25, 2014; Accepted April 27, 2014; Published April 29, 2014

Citation: Rehman HU (2014) Drug Effects on Myasthenia Gravis. J Clin Case Rep 4: e135. doi:10.4172/2165-7920.1000e135

Copyright: (c) 2014 Rehman HU. This is an open-access article distributed under the terms of the Creative Commons Attribution License, which permits unrestricted use, distribution, and reproduction in any medium, provided the original author and source are credited. 
9. Brumlik J, Jacobs RS (1974) Myasthenia gravis associated with diphenylhydantoin therapy for epilepsy. Can J Neurol Sci 1: 127-129.

10. Hirose K, Yamaguchi H, Oshima Y, Choraku M, Hirono A, et al. (2008) Severe respiratory failure and torsades de pointes induced by disopyramide in a patient with myasthenia gravis. Intern Med 47: 1703-1708.

11. Herishanu $Y$, Rosenberg $P$ (1975) Letter: beta-Blockers and myasthenia gravis Ann Intern Med 83: 834-835.

12. Verkijk A (1985) Worsening of myasthenia gravis with timolol maleate eyedrops. Ann Neurol 17: 211-212.

13. Swash M, Ingram DA (1992) Adverse effect of verapamil in myasthenia gravis. Muscle Nerve 15: 396-398.

14. Pina Latorre MA, Cobeta JC, Rodilla F, Navarro N, Zabala S (1998) Influence of calcium antagonist drugs in myasthenia gravis in the elderly. J Clin Pharm Ther 23: 399-401.

15. O'Riordan J, Javed M, Doherty C, Hutchinson M (1994) Worsening of myasthenia gravis on treatment with imipenem/cilastatin. J Neurol Neurosurg Psychiatry 57: 383.

16. Absher JR, Bale JF Jr (1991)Aggravation of myasthenia gravis by erythromycin J Pediatr 119: 155-156.

17. Barrons RW (1997) Drug-induced neuromuscular blockade and myasthenia gravis. Pharmacotherapy 17: 1220-1232.

18. Frank JH, Cooper GW, Black WC, Phillips LH $2^{\text {nd }}(1987)$ lodinated contrast agents in myasthenia gravis. Neurology 37: 1400-1402. 